\title{
"YO SII TE CREO». ESTEREOTIPOS SEXISTAS HACIA LAS VÍCTIMAS DE AGRESIÓN SEXUAL. UN ESTUDIO DE CASO SOBRE LA AUDIENCIA PROVINCIAL DE BALEARES (2018)
}

\section{«I BELIEVE YOU». SEX-STEREOTYPES TO SEXUAL ASSAULT VICTIMS. A CASE STUDY FOR THE BALEARIC COURT (2018)}

\author{
Esmeralda Ballesteros Doncel (*). Universidad Complutense de Madrid - España \\ eballest@ucm.es \\ Francisca Blanco Moreno (*). Universidad Complutense de Madrid - España \\ fblancom@ucm.es
}

Resumen: La credibilidad de las víctimas de agresión sexual es a menudo cuestionada por algunos de los profesionales que enjuician la delincuencia sexual. A menudo, este escepticismo está basado en la pervivencia de estereotipos sexistas. Uno de ellos se refiere a qué se entiende que es una 'violación real'. En el imaginario colectivo pervive el mito de que, la violación real implica la participación de un extraño armado, que ataca a una mujer de forma violenta durante la noche, causando graves heridas en las víctimas. Este artículo, que se presenta como un estudio de caso exploratorio, se examinan sentencias judiciales, emitidas por la Audiencia Provincial de Baleares en el año 2018 y que dictan un fallo absolutorio a los procesados. El estudio analiza cuatro factores, que en otras investigaciones empíricas se habían identificado como predictores de impunidad: el vínculo entre la víctima y el procesado, la violencia del ataque, el carácter de la víctima antes y después de la agresión sexual y, las asimetrías en la carga de la prueba. Los hallazgos corroboran la pervivencia de estereotipos de género.

Palabras clave: Agresión sexual, credibilidad víctimas, estereotipos, mitos de la violación, impunidad.

\begin{abstract}
The credibility of victims of sexual assault is often questioned by some of the professionals who prosecute sexual crime. Often this skepticism is based on the persistence of sexist stereotypes. One of them refers to what is understood to be a "real violation." In the collective imagination, the myth survives that real rape involves the participation of an armed stranger, who attacks a woman violently at night, causing serious injuries to the victims. This article, which is presented as an exploratory case study, examines judicial decisions, issued by the Provincial Court of the Balearic Islands in 2018 and which issue an acquittal to the defendants. The study analyzes four factors, which in other empirical investigations had been identified as predictors of impunity: the link between the victim and the accused, the violence of the attack, the character of the victim before and after the sexual assault, and asymmetries in the burden of proof. The findings corroborate the persistence of gender stereotypes.
\end{abstract}

Keywords: Sexual assault, victim credibility, stereotypes, rape myths, impunity. 


\section{Introducción}

En los últimos años asistimos, en todo el mundo, a una visibilización mediática de las agresiones sexuales contra las mujeres; un hecho diario, continuo y universal (Segato, 2003; FRA, 2014; Solnit, 2016). En España, el caso 'San Fermín' (2016) ha supuesto un punto de inflexión en la conciencia social y ha contribuido a revelar la importante incidencia de la criminalidad sexual, sus efectos en la vida de las víctimas y, lo que es más importante, está revirtiendo 'el silencio' en coraje colectivo, que pretende impulsar cambios sustantivos a nivel cultural, jurídico y político.

Desde hace décadas, distintas especialistas en los ámbitos de la criminología (Daly y Bouhours, 2010; Spohn y Tellis, 2012), el derecho penal (Mackinnon, 1987, 2017; Asúa, 2008), la psicología social (Krahé, 2008; Schuller et al., 2010; Waterhouse et al. 2016), la sociología jurídica (Smart, 1993; Pitch, 2010; Salanueva y Zaikoski, 2015; Tardón Recio, 2017) y decenas de miles de activistas feministas vienen denunciando el círculo de impunidad en el que se desenvuelven las violencias sexuales. Entre las conclusiones que se derivan de sus contribuciones, se problematiza sobre la supuesta 'neutralidad' de los distintos agentes que intervienen en los procesos de registro, reconocimiento y enjuiciamiento de la criminalidad sexual y, ello implica admitir que, muchas de sus actuaciones se desenvuelven desde una ilógica inercia de estereotipos hacia las víctimas.

La impunidad, se nutre de diversos factores: el silencio de las víctimas ${ }^{1}$, las dificultades para la identificación de los agresores, la insuficiente carga probatoria o, el cuestionamiento del testimonio de las denunciantes. Es justamente este último aspecto, uno de los que más reactividad social ha generado en las movilizaciones feministas de apoyo a la víctima del caso San Fermín. En el transcurso del juicio oral en la A.P. de Navarra, se conoció que un abogado de la defensa presentó como prueba un informe de un detective privado sobre la vida de la víctima, había sido vigilada en las semanas posteriores a la agresión. El solo hecho de que, el tribunal sometiera a consideración su aceptación, provocó diversas acciones de repulsa y en la decena de concentraciones convocadas en distintas ciudades españolas, el viernes 17 de noviembre de 2017, se viralizó el lema: "Hermana, yo sí te creo" (Angulo, 2019: 87-88).

La pervivencia de estereotipos sexistas conllevan, entre otros efectos, dudar del testimonio de las víctimas, minimizar la gravedad de su relato o, lo que es más grave, responsabilizarlas de lo ocurrido. Resulta curioso advertir que, cuando se interpone una denuncia por violencia sexual la primera sospechosa sea la denunciante. ¿Qué factores pueden conducir a no creer en una denuncia? ¿Por qué una víctima de violencia sexual no va a decir la verdad? Considerando la hostilidad de los procesos judiciales y su demora en el tiempo ¿Por qué las pocas víctimas qué se atreven a denunciar son

\footnotetext{
${ }^{1}$ En 2014, el informe de la Agencia Europea de Derechos Fundamentales (FRA) señalaba que sólo un 14\% de las víctimas de violencia sexual denunciaron el ataque.
} 
'cuestionadas' más severamente que sus agresores? En estos últimos años, los movimientos feministas han impulsado reacciones de indignación social contra la tendencia a responsabilizar a las víctimas de las agresiones porque, según los criterios del orden social hegemónico, estaban 'en el lugar inadecuado', 'a horas inadecuadas', 'con ropas inadecuadas', 'en compañía inadecuada', etc. Asimismo, los nuevos activismos feministas han tejido redes desde la experiencia de sujetos 'anónimos' y han alcanzado un inédito poder de representación pública, subvirtiendo las sospechas de que los testimonios de las víctimas son denuncias falsas (Gilmore, 2017), e impulsando reflexiones para una resignificación de los términos consentimiento, intimidación, violencia o resistencia.

En este artículo se propone una indagación exploratoria para examinar la presencia de estereotipos sexistas en el razonamiento jurídico de procesos judiciales seguidos por agresión sexual $^{2}$. El análisis trata de identificar la presencia de patrones de discriminación en sentencias que alcanzan un fallo absolutorio.

\section{Características del estudio de caso}

En este artículo se ofrecen los resultados de una prospección para la Audiencia Provincial de Baleares, en el año 2018. Se eligió esta jurisdicción como 'estudio de caso exploratorio', entre otros motivos porque Baleares es una de las Comunidades Autónomas, junto a las ciudades de Melilla y Ceuta, con una de las más altas tasas de criminalidad sexual (Tabla 1). La localización de sentencias se realizó a través de la base de datos CENDOJ3 y se programó una búsqueda focalizada en el tipo penal más grave que reconoce el Código Penal por delitos 'Contra la libertad sexual', esto es, la agresión sexual (arts. 178-180). Los criterios de selección se sirvieron de seis campos de búsqueda simultáneos: jurisdicción (penal), tipo de resolución (sentencia), órgano judicial (A. Provincial - Baleares), fecha de resolución (01/01/2018 a 31/12/2018) y el descriptor contenido en el tesauro CENDOJ 'agresión sexual'.

\footnotetext{
${ }^{2}$ Este artículo es uno de los primeros resultados del Grupo de investigación SEXVIOL que estudia diversos aspectos de las violencias sexuales y está formado por las siguientes investigadoras: Concepción Fernández Villanueva, Francisca Blanco Moreno, Tebelia Huertas Bartolomé, Elisa García Mingo, Carmen Ruiz Repullo, Empar Aguado Bloise, Ma José Rubio Martín, Tania García Sedano y Esmeralda Ballesteros Doncel.

3 El Centro de Documentación Judicial (CENDOJ), es un órgano técnico del Consejo General del Poder Judicial (CGPJ) que se encarga de la publicación de documentos jurídicos, principalmente sentencias. Este órgano ha creado una base de datos accesible y pública que contiene, según el propio CENDOJ más de cuatro millones de resoluciones judiciales y permite realizar consultas avanzadas mediante la combinación de descriptores jurídicos, campos de delimitación temporal y palabras clave estructuradas en un Tesauro que facilitan una búsqueda selectiva según tipología penal. Una de las grandes ventajas de esta base de datos es que las sentencias son incorporadas de forma casi simultánea a la comunicación a las partes y estos documentos presentan una gran riqueza de información que permiten descubrir las circunstancias que concurren en los delitos procesados judicialmente. De modo que, se pueden conocer un conjunto de informaciones sensibles que las estadísticas de criminalidad sexual omiten, como, por ejemplo, si existía vinculo entre víctima y agresor, cuál era su naturaleza, el grado de ejecución de la agresión, el lugar, el tiempo, el modus operandi o, su posible reiteración.
} 
A partir de la aplicación de dichos criterios de búsqueda, CENDOJ recuperó diecisiete documentos, pero hubo que desestimar cinco sentencias pues, aunque contenían el término 'agresión sexual', eran procedimientos que enjuiciaban otros tipos delictivos (abuso sexual, inducción a la prostitución y corrupción de menores). De las doce sentencias válidas, cuatro dictaminaban una resolución absolutoria o parcialmente absolutoria (Tabla 2).

Tabla 1

Tasa general de delincuencia sexual', según CCAA y año (2010-2018)

\begin{tabular}{|l|r|r|r|r|r|r|r|r|r|r|r|}
\hline \multicolumn{1}{|c|}{ CCAA } & $\mathbf{2 0 1 0}$ & $\mathbf{2 0 1 1}$ & $\mathbf{2 0 1 2}$ & $\mathbf{2 0 1 3}$ & $\mathbf{2 0 1 4}$ & $\mathbf{2 0 1 5}$ & $\mathbf{2 0 1 6}$ & $\mathbf{2 0 1 7}$ & $\mathbf{2 0 1 8}$ & \multicolumn{1}{c|}{} & D. T. \\
\hline Andalucía & 21,12 & 20,48 & 19,31 & 19,24 & 19,67 & 20,25 & 21,90 & 24,63 & 27,90 & 21,61 & 2,89 \\
\hline Aragón & 23,01 & 20,13 & 15,93 & 17,22 & 17,13 & 19,05 & 21,93 & 20,94 & 26,44 & 20,20 & 3,32 \\
\hline Asturias & 14,11 & 11,56 & 13,83 & 11,14 & 11,77 & 13,98 & 14,00 & 14,11 & 20,13 & 13,85 & 2,66 \\
\hline Balears (IIles) & 38,52 & 37,64 & 34,21 & 36,52 & 35,71 & 37,21 & 39,92 & 46,33 & 51,73 & 39,75 & 5,66 \\
\hline Canarias & 28,23 & 24,87 & 24,78 & 22,14 & 21,19 & 24,09 & 25,21 & 29,65 & 35,25 & 26,16 & 4,31 \\
\hline Cantabria & 17,90 & 13,66 & 8,08 & 9,29 & 12,57 & 11,96 & 11,85 & 14,48 & 17,58 & 13,04 & 3,32 \\
\hline Castilla y León & 11,53 & 10,87 & 12,14 & 9,44 & 11,26 & 11,41 & 11,81 & 15,17 & 18,22 & 12,43 & 2,65 \\
\hline Castilla La Mancha & 14,63 & 15,46 & 12,16 & 14,71 & 13,71 & 15,01 & 17,05 & 18,26 & 24,13 & 16,12 & 3,48 \\
\hline Cataluña & 24,29 & 24,70 & 21,57 & 21,80 & 24,96 & 25,68 & 29,90 & 29,28 & 34,18 & 26,26 & 4,11 \\
\hline Ceuta & 22,34 & 15,78 & 17,85 & 19,01 & 11,77 & 20,17 & 46,14 & 29,43 & 58,72 & 26,80 & 15,62 \\
\hline Melilla & 49,98 & 43,33 & 32,18 & 45,41 & 36,68 & 35,05 & 59,28 & 33,67 & 31,26 & 40,76 & 9,49 \\
\hline C. Valenciana & 25,49 & 24,31 & 22,91 & 21,55 & 22,84 & 24,41 & 27,08 & 27,28 & 31,83 & 25,30 & 3,11 \\
\hline Extremadura & 14,36 & 16,05 & 12,09 & 13,32 & 13,00 & 15,00 & 14,43 & 14,17 & 19,48 & 14,66 & 2,14 \\
\hline Galicia & 13,90 & 14,24 & 12,87 & 12,29 & 13,72 & 15,88 & 15,96 & 16,95 & 19,84 & 15,07 & 2,35 \\
\hline Madrid & 20,73 & 22,24 & 20,16 & 20,32 & 21,71 & 21,98 & 23,98 & 27,29 & 30,62 & 23,23 & 3,55 \\
\hline Murcia & 19,70 & 21,50 & 19,33 & 19,56 & 25,70 & 25,08 & 25,87 & 26,59 & 32,33 & 23,96 & 4,33 \\
\hline Navarra & 20,41 & 17,60 & 17,22 & 18,46 & 24,97 & 21,70 & 34,18 & 36,07 & 41,85 & 25,83 & 9,18 \\
\hline País Vasco & 19,14 & 19,91 & 16,92 & 18,11 & 17,86 & 18,77 & 17,99 & 22,79 & 29,97 & 20,16 & 4,04 \\
\hline Rioja (La) & 15,20 & 19,20 & 14,52 & 11,49 & 12,54 & 15,45 & 15,20 & 18,07 & 19,32 & 15,67 & 2,75 \\
\hline T. NACIONAL & $\mathbf{2 1 , 1 8}$ & $\mathbf{2 0 , 9 6}$ & $\mathbf{1 9 , 0 6}$ & $\mathbf{1 8 , 9 3}$ & $\mathbf{2 0 , 2 4}$ & $\mathbf{2 1 , 1 7}$ & $\mathbf{2 3 , 2 9}$ & $\mathbf{2 5 , 1 1}$ & $\mathbf{2 9 , 5 0}$ & $\mathbf{2 2 , 1 6}$ & $\mathbf{3 , 3 7}$ \\
\hline
\end{tabular}

Fuentes: Portal Estadístico de la Criminalidad e Instituto Nacional de Estadística. Elaboración propia

Examinando los cuatro documentos, se advierten características similares en tres sentencias ( $\operatorname{casos} 1,2$ y 4). El caso número 3, se ha identificado como una acusación falsa, en tanto queda demostrado que no hubo una acción de forzar el consentimiento de la denunciante, por lo que será desestimada en el análisis 5 .

Tasa general de delincuencia sexual $=\frac{\text { TOTAL Denuncias contra la libertad sexual }}{\text { TOTAL Población }} \times 100.000$

${ }^{5}$ Aunque en la sentencia SAP IB 1676/2018 se haya demostrado que la denunciante realizó una acusación falsa, puesto que el intercambio sexual fue consentido, prevalece un delito contra la libertad sexual, en tanto que la relación se establece con una menor ( 14 años) que mantiene con el procesado una diferencia etaria de diez años (24 años) y que el Código Penal lo considera sancionable, porque el adulto puede 
Tabla 2

Identificación de casos que han obtenido una sentencia absolutoria por la A.P. de Baleares en el año 2018 sobre una causa de enjuiciamiento por 'agresión sexual'

\begin{tabular}{|c|c|}
\hline Caso & Resumen de los hechos \\
\hline 1 & $\begin{array}{l}\text { Ciudadana inglesa (p. } 3 \text { ), de edad indeterminada, conoce al procesado porque han } \\
\text { interactuado varias noches previas en la discoteca donde él trabaja (Beach House). Una } \\
\text { noche, mientras el enjuiciado cumple con su jornada laboral, la demandante acompaña al } \\
\text { procesado a fumar un cigarrillo a una terraza anexa al local. El procesado comienza a tocarla } \\
\text { los genitales y ella se aparta, entonces él la agarró por los brazos y la bajó los pantalones para } \\
\text { penetrarla vaginalmente. Tras estos hechos ella se queda inmóvil en las escaleras y él la } \\
\text { agarra de las muñecas para que vuelva a entrar en la discoteca. }\end{array}$ \\
\hline 2 & $\begin{array}{l}\text { Mujer británica, } 28 \text { años, afrodescendiente ( } p \text {. 16) denuncia la violación de un senegalés de } \\
40 \text { años, con antecedentes penales, al que conocía por sus viajes de vacaciones a Ibiza y con } \\
\text { el que mantuvo, cinco años atrás una relación sexual consentida. La noche de la agresión } \\
\text { estaba en una fiesta de despedida de soltera y había bebido mucho y salió a tomar el aire para } \\
\text { despejarse. El procesado se ofreció acompañarla y a pasear para que se despejara. Ella } \\
\text { accedió, en el transcurso del paseo, la empujó en el interior de un edificio, agrediéndola } \\
\text { sexualmente. Unas horas después acude a la policía a presentar denuncia, pero la derivan a } \\
\text { la Guardia Civil; donde le comunican que como es domingo no hay intérpretes de inglés y que } \\
\text { 'debe volver el lunes', omitiendo la urgencia de realizar un reconocimiento físico, } \\
\text { ginecológico y psicológico. }\end{array}$ \\
\hline 3 & $\begin{array}{l}\text { Mujer, } 14 \text { años, se cita con un varón de } 24 \text { años, en la casa de la denunciante donde } \\
\text { mantienen relaciones sexuales (el acusado afirma que consentidas, la demandante afirma } \\
\text { que forzadas). Posteriormente, la joven le pide al demandado que le ayude a comprar la } \\
\text { píldora poscoital y el se desentiende. Transcurrida una semana, la joven acude a un hospital } \\
\text { afirmando que ha sido forzada sexualmente. Si bien en el proceso judicial quedó demostrado } \\
\text { que no hubo agresión sexual, el tribunal tuvo que valorar el perjuicio de un intercambio sexual } \\
\text { con una menor de } 16 \text { años (sin capacidad jurídica para el intercambio sexual). }\end{array}$ \\
\hline 4 & $\begin{array}{l}\text { Mujer, de edad no determinada, se cita a la finalización de la jornada laboral de un camarero } \\
\text { de discoteca (varón de } 19 \text { años), al que ha conocido dos meses antes y al que denominaremos } \\
\text { EL CITADO. Los acompaña otro camarero de la discoteca (varón de } 19 \text { años) al que } \\
\text { denominaremos EL ACOMPAÑANTE. Se trasladan en un coche a una casa abandonada y } \\
\text { acceden a una habitación con colchón, sábanas y velas. EL CITADO propone un trio, la }\end{array}$ \\
\hline
\end{tabular}

incurrir en un 'aprovechamiento de la inmadurez de la víctima'. Así lo entiende el Ministerio Fiscal, (p. 2) que califica los hechos enjuiciados como "constitutivos de un delito de abuso sexual a menor de dieciséis años, previsto y penado en el artículo 183.1 y 3 del Código Penal, solicitando la pena de doce años de prisión". Teniendo en cuenta las recomendaciones de UN-UNICEF, esta especial protección a las adolescentes está orientada a prevenir riesgos relacionados con la salud sexual y reproductiva, incluyendo el embarazo no deseado o precoz y la exposición a enfermedades de transmisión sexual. $Y$, de hecho, esta es la principal preocupación de la demandante, que reclama a su 'amante' la responsabilidad de adquirir una píldora postcoital para evitar el posible embarazo, manifestándose en este hecho la inmadurez en la gestión de sus deseos y, obviando de forma anticipada, las consecuencias de realizar prácticas de riesgo que hay que solucionar a posteriori. Pero, sobretodo, pone al descubierto, el desentendimiento, y por tanto, el 'aprovechamiento' del adulto de las consecuencias de tener sexo de riesgo con una adolescente. En este sentido cabe citar la circular 1/2017, de 6 de junio, de la Fiscalía General del Estado sobre la interpretación del art. 183 quater del Código Penal. 
víctima no acepta. Se inicia una relación sexual, el CITADO penetra vaginalmente a la víctima y obliga a que practique una felación al ACOMPAÑANTE. El citado se pone violento y penetra a la víctima hasta hacerla sangrar. Ella pide que pare, grita y sale huyendo desnuda. Es auxiliada por un viandante que la lleva hasta la recepción de un hotel, desde donde se llama a la Guardia Civil y se inicia protocolo por agresión sexual.

\section{Persistencia en la incredibilidad hacia las víctimas de violencia sexual}

A María no la creyeron, tenía 8 años. Tras volver de pasar el fin de semana con su padre, presentaba síntomas de infección vaginal y contó a su madre que 'papá le tocaba los genitales' y que 'no quería ir más con él'. La madre denunció (marzo de 2015) que su hija era víctima de abusos sexuales. En enero de 2016, el caso fue archivado por una jueza, las pruebas periciales no eran 'tan convincentes' como para creer en el testimonio de María. En junio de 2016, María volvió a ver a su padre, pero esta vez, registró una conversación que le incriminaba con una pequeña grabadora escondida en su calcetín ${ }^{6}$. La madre volvió a denunciar los hechos y la jueza responsable reabrió el caso. La historia de María no es un suceso excepcional, los informes de Save the Children, Ojos que no quieren ver (2017), y Amnistía Internacional, Ya es hora de que me creas (2018), advierten de la persistencia de prejuicios hacia las víctimas de violencia sexual.

Las Ciencias Sociales utilizan el término 'estereotipo' para referirse a simplificaciones o desfiguraciones de la realidad que creemos ciertas. En el mismo sentido y dentro del ámbito de la violencia sexual se han desarrollado conceptos teóricos más elaborados como el de 'mitos de la violación' y el de 'cultura de la violación' para denunciar que la violencia sexual no es una conducta aislada, cometida por varones disfuncionales, sino un hecho cotidiano y universal (Solnit, 2016); los mitos alegan bases biológicas al origen delictivo (el irrefrenable e insaciable deseo sexual masculino) o, señalan las ambivalencias en la actitud de las mujeres, que pese a su aparente recato, se excitan al ser forzadas y disfrutan de ser violadas (Browmiller, 1975). La cultura de la violación alimenta la creencia de que las mujeres cuando dicen 'NO' de palabra, están queriendo decir 'SI' desde el deseo, lo que implica legitimar el cuestionamiento generalizado de sus testimonios, $y$, en consecuencia, se explicaría así la baja tasas de condenas (Daly y Bouhours, 2010).

Kelly et al. (2005) consideran que los factores que explican la baja tasa de condenas se centran en la insuficiente carga probatoria, bien por los lábiles hallazgos de los informes forenses, bien porque la agresión no dejó evidencias 'incontestables' de violencia en los cuerpos de las víctimas o, porque estas no estaban en shock, bien

\footnotetext{
${ }^{6}$ RINCÓN, Reyes (2016). "La juez reabre el caso de la niña que grabó a su padre para denunciar abusos", El País 21-septiembre, edición digital. Recuperado de la siguiente dirección URL: https://elpais.com/politica/2016/og/20/actualidad/1474393389_739441.html
} 
porque no hubo testigos o, las testificales no alcanzan la suficiente verosimilitud, para considerar cierto el testimonio de la denunciante. Estas circunstancias, a menudo, propician que el fallo judicial se base en la contraposición de las declaraciones testificales de la víctima frente al procesado (Krahé et al., 2008).

La persistencia de estereotipos y mitos en torno a la delincuencia sexual no sólo atañe a tener una percepción equivocada de la realidad, sino que, además, influye en las actitudes y prácticas de todos los agentes que intervienen cuando se conoce un nuevo caso: policía, médicos, psicólogos y operadores jurídicos (Waterhouse et al., 2016). La importancia de este fenómeno ha sido reconocida por el Comité CEDAW en la Recomendación general núm. 33 sobre el acceso de las mujeres a la justicia (2015):

Los estereotipos distorsionan las percepciones y dan lugar a decisiones basadas en creencias preconcebidas y mitos, en lugar de hechos. Con frecuencia, los jueces adoptan normas rígidas sobre lo que consideran un comportamiento apropiado de la mujer y castigan a las que no se ajustan a esos estereotipos. El establecimiento de estereotipos afecta también a la credibilidad de las declaraciones, los argumentos y los testimonios de las mujeres, como partes y como testigos. Esos estereotipos pueden hacer que los jueces interpreten erróneamente las leyes o las apliquen en forma defectuosa. Esto tiene consecuencias de gran alcance, por ejemplo, en el derecho penal, ya que dan por resultado que los perpetradores no sean considerados jurídicamente responsables de las violaciones de los derechos de la mujer, manteniendo de esta forma una cultura de impunidad. En todas las esferas de la ley, los estereotipos comprometen la imparcialidad y la integridad del sistema de justicia, que a su vez puede dar lugar a la denegación de justicia, incluida la revictimización de las denunciantes. (párrafo 26)

Uno de los mitos más extendidos es que la violación tradicional es la que sucede en lugares oscuros, por extraños, con violencia e intimidación. Susan Estrich (1986, p. 1092) afirmaba que los operadores judiciales consideran más creíble la denuncia de agresión sexual cuando responde al patrón de la 'violación real' (real rape), es decir, cuando un extraño armado ataca a una mujer de forma violenta durante la noche, en un lugar aislado, provocando en las mujeres heridas graves a consecuencia del ataque. Sin embargo, la mayoría de los casos de violencia sexual se desvían en uno o varios aspectos de ese patrón, pues en los ataques se usa menos fuerza o, no se inflige ningún daño físico, porque las amenazas pueden ser sutiles, porque victima y procesado se conocían, porque el escenario de la agresión no es un callejón sino un dormitorio, porque el contacto inicial no fue un secuestro sino una cita, porque aunque la víctima se resiste al ataque, no lo hizo con suficiente vehemencia (Waterhouse et al., 2016). En tales casos, los tribunales son renuentes a considerar que se produjo una agresión sexual. 
El mantenimiento de los estereotipos está en relación con la desatención política de la violencia sexual, la falta de fuentes estadísticas para conocer su magnitud real y, por supuesto, la tendencia a minimizar sus graves efectos en las víctimas que lo soportaban. Una estrategia para revertir los 'mitos' exige el desarrollo de investigaciones empíricas de carácter interdisciplinar que permitan identificar las causas de la impunidad, para diseñar políticas públicas orientadas a la prevención, investigación, intervención y reparación de las violencias sexuales.

\section{Análisis de tres sentencias absolutorias. Identificación de patrones de discriminación sexista}

Con todas las reservas que han de tenerse en cuenta en relación con este estudio de caso7, en esta sección se procede a analizar tres sentencias absolutorias que emitió la Audiencia Provincial de Baleares en el año 2018, por enjuiciamiento del delito de agresión sexual (Tabla 2). Para ello se examinarán cuatro factores que en otras investigaciones empíricas se han identificado como predictores de impunidad (Daly y Bouhours, 2010; Salanueva y Zaikoski, 2015; Toledo et al. 2016). A saber: a) Vínculo entre la víctima y el procesado, b) Presencia de fuerza y/o intimidación, c) Carácter y credibilidad de la víctima antes y después de la agresión y d) La carga de la prueba.

a) Vínculo entre la víctima y el procesado

Considerando la definición de Susan Estrich (1986, p. 1092) sobre 'violación real' que se reconoce por los operadores judiciales como la violación tradicional, cruenta y creíble: "un extraño pone un arma en la cabeza de su víctima, amenaza con matarla o la golpea y lvego asalta su cuerpo, causándole lesiones". En las tres sentencias estudiadas, la víctima conocía en algún grado a su agresor. En el caso 1, la denunciante de nacionalidad británica había interactuado con el camarero del local Beach House en las noches previas a la agresión. En el caso 2, la denunciante conocía a su agresor porque ella, británica y afrodescendiente, viajaba de forma regular a Baleares en sus vacaciones y cinco años antes había tenido con él un 'affaire'. En el caso 4, la denunciante había programado un encuentro sexual con uno de los dos procesados. En otras palabras, todas las sentencias absolutorias analizadas, en relación con el vínculo denuncianteprocesado, se distancian del patrón definido como 'violación real'. Así se corrobora uno de los mitos de la violación 'real' en el razonamiento de la magistrada que emite voto particular en la sentencia núm. 4: "los hechos enjuiciados no se refieren a una agresión sexual por parte de un total desconocido, sino a lo ocurrido en el transcurso de una relación sexual que la denunciante había consentido mantener" (SAP IB 2629/2018, p. 23).

\footnotetext{
7 Somos conscientes que se trata sólo de un estudio de caso, basado en el análisis de tres sentencias y, por tanto, sin capacidad alguna de inferencia. No obstante, pensamos que es una prospección válida y consistente con los hallazgos de estudios mas amplios, pero y sobretodo creemos que invita a ser replicada para otros órganos jurisprudenciales, ampliado los años de observación y el número de territorios en estudio.
} 
De esta redacción se deducen dos cuestiones, el énfasis en que el procesado no es un desconocido y que la magistrada no considera que una relación sexual planificada pueda convertirse en una agresión sexual.

Estos resultados son consistentes con los hallazgos de otras investigaciones empíricas. En el informe del grupo de investigación Antígona (Toledo, et al. 2016: 7880) se señala que en el $51 \%$ de las 45 sentencias estudiadas, la víctima y el agresor se conocían. Además, en las 16 sentencias exculpatorias "llama poderosamente la atención que todas las absoluciones, excepto 2, se dicten para estos casos de agresores y víctimas conocidos". El informe de Save the Children (2017, p.13), Ojos que no quieren ver, afirma que en los casos de abuso infantil, las víctimas conocían a su agresor en seis de cada diez casos. Según Jo Lovett y Liz Kelly (2009), en el 48 por ciento de los casos de agresión sexual examinados, la víctima conocía al autor antes del asalto, mientras que solo el $22 \%$ de las víctimas informaron que fueron agredidas sexualmente por un extraño. En el mismo sentido, según la estadística publicada por Oficina Federal de Policía Criminal alemana-BKA, sólo el $23 \%$ de todos los casos de violación denunciados en 2015, fueron cometidos por un extraño (Bundeskriminalamt, 2015, tabla 92). Estos resultados ponen al descubierto que el violador desconocido es un patrón minoritario, sin embargo, sigue siendo un poderoso factor para cuestionar el testimonio de las víctimas "Se descree de las mujeres que tienen o han tenido relaciones afectivas o son conocidas de sus victimarios, mientras que es evidente que el desconocimiento entre ambos protagonistas del delito es una situación que se valora a favor de la víctima" (Salanueva y Zaikoski, 2015, p. 246).

\section{b) Presencia de fuerza y/o intimidación}

En esta sección se quiere examinar el determinismo de que una agresión sexual, para ser creíble, debe estar rodeada de violencia y, que esta, debe verificarse 'científicamente' mediante huellas corporales. En España, la denuncia de un delito contra la libertad sexual implica la activación de un protocolo de actuaciones que conllevan de forma inmediata la declaración en sede policial y la exploración de la víctima por parte de profesionales de la medicina y la psicología forenses. La exploración física, ginecológica y psicológica serán documentadas mediante informes y si se inicia un proceso de instrucción, se aportarán como pruebas documentales. Algunos expertos coinciden en señalar que el registro de pruebas periciales debe realizarse con celeridad, lo que aconseja que la denuncia debe producirse en las 24 horas posteriores a la agresión.

En nuestro estudio de caso todas las víctimas denunciaron los hechos de forma inmediata $y$, por tanto, contienen informes periciales tempranos, aunque en ninguno de los casos se ejerció una violencia cruenta contra las víctimas, de los informes se deduce que el uso de la violencia fue 'bajo'. En ningún caso se emplearon armas, ni amenazas. En el caso 1, el informe forense apreció improntas digitales en ambos brazos y muñecas, un leve desajuste psicológico y labilidad emocional. En el caso 2, no se 
diagnosticó lesión alguna y, en el caso 4, se dictaminó sangrado vaginal, equimosis amplia en el glúteo y restos hemáticos. En este sentido, el grupo de investigación Antígona considera que las lesiones físicas "siguen constituyendo un apoyo del testimonio de la víctima, pero en ocasiones se vuelven un elemento condicionante: en la medida en que no hay lesiones, no se corrobora el hecho y puede que no llegue a configurarse como delito" (Toledo et al., 2016, p.82).

En el caso 4, se aprecia de forma nítida en el razonamiento de la magistrada, que emite voto particular con sentido absolutorio, la creencia de que debe existir una relación directa entre lesiones y la credibilidad de la denuncia: "Los demás datos médicamente objetivados no me parecen concluyentes ya que, los restos hemáticos son escasos, y así se plasma desde el informe inicial y tampoco se advirtió por la forense ninguna laceración" (SAP IB 2629/2018, p. 24)

De hecho, se puede apreciar que el razonamiento jurídico orientado a la absolución resalta la ausencia de violencia. En el caso 1 , tras la denuncia y la apertura del proceso de instrucción, la víctima ratificó los hechos denunciados en sede judicial, pero la ponente de la sentencia quiere enfatizar que, en esa declaración "Consta expresamente, por la testigo, que no hubo fuerza" (SAP IB 933/2918, p. 6)

Mucho más problemático resulta verificar que la ausencia de lesiones vaginales, especialmente en mujeres adultas con una vida sexual activa, podría interpretarse como ausencia de daño y, deducirse como ausencia de delito:

Personado en dicho Servicio, se encuentra la informada en compañía de una amiga. Se le interroga acerca de las posibles lesiones físicas tanto en superficie corporal como genitales y manifiesta no tener lesión alguna. Que mantiene relaciones sexuales consentidas con asiduidad por lo cual la exploración ginecológica, en ausencia de lesiones, carece de interés criminalístico. Igualmente, se nos transmite que se ha realizado higiene de forma reiterada, asï como el tiempo transcurrido desde los hechos, impiden la aplicación del protocolo de sumisión química. (SAP IB 973/2018, p. 20)

Incluso el tribunal, cuando realiza su razonamiento orientado a la absolución del procesado puede incurrir en contradicciones, al desestimar o considerar insuficientes los informes de estrés postraumático aportados por la víctima:

Sobre las consecuencias psicológicas que los hechos denunciados han tenido en Rosaura, contamos con lo manifestado por ésta, por su prima y los documentos aportados al inicio del juicio oral sobre su repercusión en el trabajo y en su vida. Pero éstos, que sí son un dato corroborador de lo que cuenta, no son suficientes ante las conclusiones que hemos dejado expuestas sobre el resto del resultado probatorio. (SAP IB 973/2018, p. 23) 
Unos de los aspectos que más ha llamado nuestra atención es advertir una cierta ambigüedad en las conclusiones de los informes forenses que describen las exploraciones físicas y ginecológicas, pues a menudo la redacción expresa un diagnóstico de probabilidad, en términos de 'son compatibles con', pero 'no demuestran que': "Finalmente establece una relación de compatibilidad entre las lesiones y el tipo de agresión referido, con el matiz de que su valoración no supone la demostración del hecho sino, exclusivamente, la posibilidad de que se hayan producido mediante el mecanismo referido" (SAP IB 933/2018, p. 7).

Tampoco puede obviarse que un informe pericial puede contener una omisión en la especificidad de la exploración de la víctima. En el caso 2, en el transcurso del juicio oral, el tribunal interrogó a la víctima sobre si la agresión le dejó equimosis en brazos o piernas: "Rosaura explicó que por su piel oscura [la víctima es afrodescendiente] no tenía hematomas ni en las piernas ni en los brazos, pero tenía dolorido el brazo y la vulva" (SAP IB 973/2018, p. 16). Este es un dato circunstancial importantísimo, puesto que las equimosis poseen un extraordinario interés medico legal, ya que proporcionan valiosos indicios para la reconstrucción de la violencia. Tradicionalmente, los médicos de acuerdo con su experiencia utilizan la evaluación visual para determinar la edad de una equimosis, pero esta técnica ha demostrado ser inexacta y poco fiable. Randeberg (2005) concluyó que el color de la equimosis variará dependiendo de la raza del individuo (negro, blanco, mestizo, mulato); siendo los sujetos de piel oscura los que presentan mayor dificultad para el reconocimiento visual de los hematomas, puesto que la mayor concentración de melanina complica 'a simple vista' el contraste entre la piel moreteada y la piel normal.

En síntesis, las sentencias absolutorias examinadas buscan como un elemento de corroboración la presencia de lesiones corporales en las víctimas como efecto del ejercicio de la violencia y, sin embargo, el título VIII del Código Penal considera que el bien protegido es la libertad sexual, por lo que los tribunales deberían centrar su juicio en el consentimiento y no en las lesiones físicas. Con todo, no se dispone de investigaciones empíricas que señalen cuántas agresiones sexuales no producen lesiones en las víctimas.

\section{c) Carácter y credibilidad de la víctima antes y después de la agresión}

Un aspecto importante en los procesos de enjuiciamiento por agresión sexual es dilucidar la actitud de las víctimas antes y después de un ataque sexual. A las víctimas, para ser más creíbles, antes de la agresión, se las 'exige' el recato, de modo que si están fuera del canon de la prudencia (de fiesta, a altas horas de la madrugada, con vestimenta ligera, habían consumido alguna sustancia estimulante, etc.) los tribunales van a juzgar con más severidad su testimonio (Daly y Bouhours, 2010, p. 609).

En este estudio de caso, las tres sentencias describen que los hechos se produjeron en un contexto de ocio nocturno, con variable consumo de alcohol y de madrugada. No supone ningún descubrimiento afirmar que existe una menor tolerancia social a que las mujeres consuman alcohol de forma excesiva, en relación con los varones. De hecho, estas conductas suelen ser percibidas como comportamientos reprobables que caracterizan una cierta 'promiscuidad' en ellas. En el caso 2, la víctima reconoce ante el tribunal que, probablemente por el excesivo consumo de alcohol, no es capaz de recordar:"Reiteró que había bebido alcohol, no recordando exactamente qué o en qué 
cantidad, aunque sabía que bebió cava y algún chupito. Dijo que ese viaje era por una despedida de soltera y el objetivo era "emborrachar a la dura novia" (SAP IB 973/2018, p. 15)

Los resultados de la pregunta 6.2 de la encuesta sobre Percepción social de la violencia sexual (2017, Estudio CIS núm. 3182): "Dígame cuál es su grado de acuerdo, con la siguiente afirmación: -Si una mujer es agredida sexualmente estando borracha tiene parte de la culpa por haber perdido el control". El $65 \%$ de las personas entrevistadas manifestó su total desacuerdo con la afirmación, pero conviene indicar que se registró un alineamiento de acuerdo en un $15 \%$ de la muestra y un $20 \%$ afirmó un desacuerdo parcial (moderado o leve), en otras palabras, más de un tercio de la población (de acuerdo o parcialmente en descuerdo) trasladaría parte de la responsabilidad a la víctima. En la misma encuesta y en los mismos términos, también se preguntaba si "El alcohol es a menudo el causante de que un hombre viole a una mujer" (Pregunta 5.5). Sólo un 30\% de las personas entrevistadas manifestaron su total desacuerdo, es decir, no justificarían que el alcohol fuera un desencadenante de una violación, frente a un $68 \%$ que afirmó acuerdo con la afirmación o, un descuerdo parcial.

El estudio de Ruiz Repullo et al. (2020), basado en el análisis de 24 entrevistas en profundidad a población juvenil (de 16 a 22 años; 10 mujeres y 14 varones) confirma la tendencia al señalamiento social de aquellas chicas que realizan de forma ocasional un consumo excesivo de alcohol y advierte de que la embriaguez es utilizada por algunos chicos (de forma individual o colectiva) para abordar e insistir en mantener una relación sexual que, puede transformarse en una experiencia de violencia sexual.

El ámbito jurídico no difiere de los imaginarios sociales y mientras en las denunciantes el consumo de alcohol puede predisponer a los tribunales a restar credibilidad a sus testimonios, en el caso de los procesados, la embriaguez puede convertirse en atenuante 'muy cualificada' y rebajar sustancialmente la pena (SAP M 11157/2018).

Por otro lado, ¿qué se espera que haga una víctima tras una agresión sexual? Pese a que las reacciones emocionales de las personas son variadas, lo que se espera de una víctima tras una agresión sexual es que denuncie y esté visible y extremadamente traumatizada:

El estado de la víctima en los momentos posteriores a la ocurrencia de los hechos fue confirmado por varias personas, el recepcionista del hotel Baviera, los agentes de la guardia civil que acudieron en primer lugar y el médico forense (estaba muy nerviosa, abatida y llorando). (SAP IB 2629/2018, p. 16)

Sin embargo, en contadas ocasionas se hace alusión a los impactos de desgaste emocional que implica el proceso judicial en las víctimas. Las debilidades y fallos en los sistemas de registro, reconocimiento y enjuiciamiento de una agresión sexual pueden 
provocar un alejamiento o desentendimiento del proceso judicial. En nuestro estudio, en los casos 1 y 4, las víctimas no comparecieron en el juicio oral y este hecho puede interpretarse como impersistencia en la incriminación, uno de los criterios jurisprudenciales para dirimir la motivación fáctica (STS 794/2014):

la testigo ha decidido no persistir en su denuncia...me parece significativo que la denunciante no haya comparecido a juicio en un presunto delito que suele produce en un ámbito de intimidad, ajeno a la presencia de terceros, con las dificultades que supone la ausencia del principal testigo en orden a determinar cómo han ocurrido los hechos; circunstancia que en la sociedad actual resulta sobradamente conocida por cualquier persona incluso fuera del ámbito estrictamente jurídico. Esta ausencia deja entrever una cierta impersistencia, en línea con lo alegado por la defensa en vía de informe, en la medida en que pone de manifiesto que la denunciante se ha desconectado del proceso que ella inició mediante denuncia, sin que conste ninguna otra intervención de la misma en el procedimiento más allá de la que tuvo aquel día inicial. (SAP IB 2629/2018, p. 20)

El Tribunal Europeo de Derechos Humanos considera que el desarrollo de los procesos penales por delitos contra la libertad sexual es vivido por las víctimas como "una auténtica ordalía" (STC 174/2011 - B.O.E. núm. 2914, p. 27). No podemos perder de vista que, desde que se interpone una denuncia las víctimas tienen que testificar en como mínimo cuatro ocasiones, si recurren a una acusación particular deberán realizar una inversión económica, estarán a disposición de la justicia para testificar o someterse a pruebas periciales por un tiempo promedio de tres años, deberán sufragarse los gastos de movilidad, por no hablar del contexto de hostilidad que implica rememorar una y otra vez, la agresión. En este sentido, escribía la víctima del caso San Fermín "Tras casi tres años, este proceso por fin se ha terminado. Ha sido largo, intenso y sobre todo agotador. Lo peor no fue la situación vivida sino todo lo que vino después ..."

En el caso 1 , la víctima de nacionalidad inglesa solicitó inicialmente testificar mediante videoconferencia alegando "falta de capacidad económica para costearse el desplazamiento asi como cargas familiares, laborales y de formación académica", pero, después de realizarse por el tribunal todas las gestiones para facilitar la declaración, la víctima rehúsa la comparecencia. Este punto es muy importante, porque la fundamentación jurídica de la sentencia para fallar la absolución apela a la imposibilidad de confrontar los testimonios de víctima y procesado (SAP IB 933/2018, p. 2-5).

\footnotetext{
${ }^{8}$ Segunda carta de la víctima del caso San Fermín (2016), remitida al programa televisivo de la periodista A.R. Quintana (Telecinco) el 28 de junio de 2019.
} 
En el caso 4, la víctima de nacionalidad española y empadronada en la población de Inca, trasladó su residencia a Gran Bretaña y según el abogado de oficio asignado fue imposible su localización (SAP IB 2629/2018, p. 4-5). Sin embargo, dos de los tres miembros del tribunal admitieron la testifical de la víctima como prueba preconstituida (Art. 730 LECRIM). Una inusual práctica que viene siendo solicitada por la Fiscalía General del Estado para evitar la revictimización de menores de edad (Circular 3/2009) y que sólo se realiza en un 14 \% de los procedimientos (Save the Children, 2017, p. 18).

En el caso 2, la víctima una mujer británica, afrodescendiente, de 28 años, sí compareció en el juicio oral. Este caso es especialmente siniestro si se tienen en cuenta todas las graves irregularidades en el proceso de la denuncia, en perjuicio de la víctima:

Sobre lo ocurrido el día que fue a poner la denuncia, Rosaura explicó que fueron a la policía y le dijeron que no era el lugar y que tenia que ir a la Guardia Civil. Que, cuando llegaron al cuartel de la Guardia Civil, le explicó al guardia que quería denunciar una violación y el oficial le dijo que no entendía inglés y que esperara hasta que encontraran a alguien para traducir. Que un tal Manuel, que hablaba inglés, le preguntó qué había pasado, que le hacía preguntas en una sala de espera con mucha gente, tomaba apuntes y después el oficial se fue a una oficina. Que, al volver, esta persona volvió con unos formularios y le pidió el pasaporte. Le explicó que los domingos no había intérpretes de inglés y que tenía que volver el lunes. Que las acompañaron a ella y a su prima al hotel y les hicieron fotocopia de los pasaportes y les dijeron que volvieran al día siguiente. Que nadie le dijo que fuera al hospital. Que, el lunes, fue al hospital porque el domingo estaba como en estado de shock y no se le ocurrió ir al hospital. Que fue el lunes cuando el oficial que le tomó declaración le preguntó si había ido al hospital. Que en la exploración médica no había intérprete y el médico no hablaba inglés. Que el médico en ningún momento le exploró sus genitales y ella no entendía nada (SAP IB 973/2018, p. 14).

Si atendemos a la secuencia de derechos que reconoce el artículo 3 de la Ley 4/2015, de 27 de abril, del Estatuto de la víctima del delito, podemos apreciar su directa vulneración

Toda víctima tiene derecho a la protección, información, apoyo, asistencia y atención, así como a la participación activa en el proceso penal y a recibir un trato respetuoso, profesional, individualizado y no discriminatorio desde su primer contacto con las autoridades o funcionarios, durante la actuación de los servicios de asistencia y apoyo a las víctimas y de justicia restaurativa, a lo largo de todo el proceso penal y por un período de tiempo adecuado después de su conclusión, con 
independencia de que se conozca o no la identidad del infractor y del resultado del proceso. (p.10)

d) La carga de la prueba

En el proceso judicial de cualquier delito, el tribunal debe llegar a la convicción de que lo que testifica la víctima se ajusta a la verdad. En el caso de las violencias sexuales los hechos se producen, de forma generalizada en un contexto de clandestinidad y ocultación por lo que la carga probatoria, en muchas ocasiones se restringe al testimonio de la denunciante frente a su agresor. De modo que, la práctica jurídica va a exigir que la acusación (M. Fiscal y A. Particular) pruebe la culpabilidad del enjuiciado. Para ello se servirá de pruebas periciales, documentales y testificales y el tribunal deberá alcanzar la 'convicción de veracidad' con relación a los hechos juzgados, puesto que la pervivencia de la duda hará siempre desestimar una sanción. "Es mejor que queden libres diez culpables que un hombre inocente sea castigado", así, concluía Estrich (1986, p. 1184) su trabajo seminal, afirmando que la insuficiente carga probatoria induce a la absolución y, esta cultura jurídica tiene consecuencias directas en la vida de cualquier víctima y, por supuesto, en la impunidad delictiva.

La justicia española también se rige por este principio, consagrado como derecho constitucional fundamental en el articulo 24.2 (CE) y cuyo argumento puede fácilmente encontrarse en la jurisprudencia:

La condena de un inocente representa una quiebra absoluta de los principios básicos de libertad, seguridad y justicia que fundamentan el contrato social, como ya se ha expresado, y en consecuencia excluir dicha posibilidad constituye un objetivo esencial del enjuiciamiento penal que debe garantizarse en cualquier caso. (STS 1029/1997, 29 de diciembre de 1997)

$Y$ aquí se puede apreciar un conflicto de fuerzas contrarias: la presunción de inocencia del inculpado frente a la credibilidad del testimonio de la denunciante. De manera que nos encontramos ante una situación de 'límites de riesgo extremo' (SAP M 16443/2018). En este sentido conviene recordar la asimetría del estatus en las testificales, mientras la denunciante-víctima declara bajo juramento (la mentira, o falso testimonio, conlleva un castigo con pena de prisión); el procesado no está obligado a semejante juramento y le asiste el derecho constitucional a no declarar contra sí mismo.

En el caso 1, en la declaración en sede judicial, en el desarrollo de proceso de instrucción, el acusado negó haber mantenido contacto sexual con la denunciante. Sin embargo, en el juicio oral, conociendo que la víctima no compareció, admitió las relaciones sexuales 'consentidas' y se explicaba así el cambio en el sentido de su declaración: "no reconoció la existencia de la relación sexual porque se produjo en horario laboral y temía perder su trabajo si su jefe tomaba conocimiento de este hecho" (SAP IB 933/2018, p. 7) 
Y así ocurre en todos los casos enjuiciados que hemos estudiado; los procesados o bien no reconocen los hechos, o bien alegan que todo lo ocurrido fue consensuado. Es por ello por lo que se aprecia una asimetría desproporcionada entre los estatutos jurídicos de la víctima y el procesado. La garantía legal obliga a que toda acusación ha de probarse, pero de la misma manera que una persona acusada es inocente hasta que se demuestre lo contrario, una persona que dice ser víctima también ha de ser tratada con todas las garantías que le reconoce la legislación vigente ${ }^{9}$. Si bien existe abundante jurisprudencia para considerar que el testimonio de una víctima puede constituirse en única prueba de $\operatorname{cargo}^{10}$, en la práctica muchos tribunales, si no encuentran alguna corroboración objetiva, acaban concluyendo que la confrontación de las testificales queda 'en tablas': "De las testificales realizadas y el resultado de la pericial, junto con la documental obrante en la causa, existen ciertos elementos que vendrían a corroborar lo contado por Rosaura, pero también algunos de esos elementos pueden corroborar lo contado por el acusado" (SAP IB 973/2018, p. 18) "...estimo que la declaración prestada no resulta tan contundente, rectilínea y detallada, como aprecian mis compañeros de Tribunal, existiendo a mi juicio cuestiones dudosas referidas al hecho nuclear (lo sucedido en la noche de autos durante el trascurso de la relación sexual) que hubieran precisado de mejor aclaración" (SAP IB 2629/2018, p. 22).

El informe del grupo de investigación Antígona señala las dificultades de muchas víctimas para recordar con precisión los hechos, bien porque habían consumido alguna sustancia estimulante que les impedía recordar, bien por el estrés emocional provocado por la agresión o por los vínculos que le unen a su victimario (Toledo et al. 2016,p. 8991).

Tampoco puede obviarse que el transcurso del tiempo, opera en sentidos distintos para la víctima y el procesado; mientras a la primera le perjudica en tanto que puede olvidar ciertos aspectos, para los enjuiciados puede ser un atenuante por 'dilación indebida'. Según el informe de Save the Children, Ojos que no quieren ver (2017, p. 92), en cuatro de cada diez condenas inculpatorias se aplica el atenuante de dilación indebida y, por tanto, la condena queda rebajada.

\section{Conclusiones}

En el año 2015, el Comité CEDAW aprobaba la Recomendación general núm. 33 sobre el acceso de las mujeres a la Justicia, advirtiendo de que la pervivencia de estereotipos de género contribuye a mantener una cultura de la impunidad. De esta forma se reconocían las tesis de juristas y penalistas feministas, que llevan décadas cuestionando

\footnotetext{
${ }_{9}$ No es nuestra intención cuestionar la 'presunción de inocencia', que es la base del sistema de justicia penal, pero sí indicar que ese principio no puede anular las garantías de procedimiento hacia las víctimas (artículo 3 de la Ley 4/2015, de 27 de abril, del Estatuto de la víctima del delito).

${ }^{10}$ La jurisprudencia establece que cuando la testifical de la víctima es la única prueba de cargo se deben examinar y razonar sobre tres criterios: $1^{\circ}$ ) Ausencia de incredibilidad subjetiva, $2^{\circ}$ ) Vesrosimilitud y $3^{\circ}$ ) Persistencia en la incriminación.
} 
la 'neutralidad' y objetividad en la administración de justicia, pues como cualquier práctica procesual no está exenta de fisuras y contradicciones internas.

El discurso jurídico inserto en las sentencias judiciales contiene argumentaciones que, en no pocas ocasiones, reflejan percepciones estereotipadas hacia las víctimas de violencia sexual, mayoritariamente mujeres, y estas pueden condicionar su credibilidad $y$, por tanto, exculpar y dejar impunes las agresiones que realizan casi exclusivamente los varones, contra sus cuerpos y su libertad.

En este estudio de caso exploratorio, basado en el análisis de tres sentencias absolutorias emitidas por la A.P. de Baleares en el año 2018, se han examinado cuatro factores que en otras investigaciones empíricas habían identificado como predictores de impunidad: el vínculo entre la víctima y el procesado, la violencia del ataque, el carácter y credibilidad de la víctima antes y después de la agresión y, las asimetrías en la carga de la prueba. Estos factores no son variables que actúen de forma independiente, sino que están relacionados y su doble o múltiple presencia tiende a debilitar de forma progresiva la credibilidad de las víctimas.

Los hallazgos corroboran la pervivencia de estereotipos de género: 1) En todos los casos, la víctima y el procesado se conocían, es decir, se comprueba un distanciamiento con el mito de la violación real, donde el asaltante se configura como un desconocido. 2) En todos los casos los agresores emplearon una fuerza que, o bien no dejó lesiones físicas en las víctimas, o bien estas revistieron un carácter superficial para el tribunal, es decir, se verifica el distanciamiento del mito de que la violación real debe ser cruenta. 3) En todos los casos, la agresión se produce en un contexto de ocio nocturno, con un disímil consumo de alcohol que operaría como un factor de enjuiciamiento moral de las víctimas. 4) En dos de los tres casos examinados las víctimas no comparecieron en juicio oral y, por tanto, no pudo someterse al principio de contradicción las declaraciones de la denunciante y el procesado, aspecto que es interpretado como impersistencia en la incriminación y 5) La especial asimetría en la carga probatoria de un delito que se comete en clandestinidad y con ocultación confronta dos fuerzas muy desiguales, el supremo principio de la presunción de inocencia frente a la convicción filtrada por los criterios de ausencia de incredibilidad subjetiva, verosimilitud y persistencia en la incriminación.

Cada vez que una agresión sexual queda impune, los victimarios reciben el refuerzo para volver a vulnerar a otra(s) víctima(s), por ello para desmontar la pervivencia de estereotipos en el registro, reconocimiento y enjuiciamiento de la delincuencia sexual se necesita promover investigaciones interdisciplinares que puedan identificar las causas de la impunidad para contribuir a diseñar políticas públicas orientadas a la prevención, intervención y reparación de las violencias sexuales. En el mismo sentido, el Consejo General del Poder Judicial debe promover una formación especializada en todos los operadores que participan en la administración de justicia, para tomar conciencia de los sesgos de género y aspirar al desarrollo de prácticas igualitarias. 


\section{Bibliografía y recursos de información}

Amnistía Internacional España (2018). Ya es hora de que me creas. Un sistema que cuestiona y desprotege a las víctimas. Recuperado de: https://www.lapolitica.com/wp-content/uploads/2018/11/AMNISTIA-INTERNACloNAL-Ya-eshora-que-me-creas.pdf

Angulo Egea, M. (2919). Subjetividad y violación social. El caso de la manada. Tropelías -Revista de Teoría de la Literatura y Literatura Comparada-, 31, 86-96.

Asúa Batarrita, A. (2008). "El significado de la violencia sexual contra las mujeres y la reformulación de la tutela penal en este ámbito. Inercias Jurisprudenciales", en LAURENZO, P. et al. (eds.), Género, violencia y derecho. Valencia, España: Tirant lo Blanch.

Bundeskriminalamt (Oficina Federal Alemana de Policía Criminal -BKA). (2015). Polizeiliche Kriminalstatistik 2015: Standard Übersicht Opfertabellen (Tabla 92). Recuperado https://www.bka.de/DE/Aktuellelnformationen/StatistikenLagebilder/Polizeilic heKriminalstatistik/PKS2015/Standardtabellen/standardtabellenOpfer.html

Cazorla González, C. (2019). Carencias y desafíos de las estadísticas oficiales para la medición de la violencia sexual en España (2010-2018). Anuario Internacional de Criminología y Ciencias Forenses, 4, 15-62.

Daly, K. y Bouhor, B. (2010). Rape and Attrition in the Legal Process: A Comparative Analysis of Five Countries. Crime and Justice, 39 (1), 565-650.

Estrich, S. (1986). Rape. The Yale Law Journal, 95 (6), 1087-1184.

Estrich, S. (1987). Real Rape. How the Legal System Victimizes Women Who Say No, Cambridge-Massachusetts, UK.: Harvard University Press.

FRA - The European Union Agency for Fundamental Rights- (2014). Violence against women: an EU-wide survey. Main results report, Luxembourg: Publications Office of the European Union.

Gilmore, L. (2017). Tainted Witness: Why We Doubt What Women Say About Their Lives, New York, EEUU: Columbia University Press.

Kelly, L., Lovett, J., y Regan, L. (2005). A Gap or a Chasm?: Attrition in Reported Rape Cases. Home Office Research Studies, 293, London,UK.: Home Office Research, Development and Statistics Directorate.

Krahé, B., Temkin, J., Bieneck, S. Y Berger, A. (2008). Prospective lawyers' rape stereotypes and schematic decision making about rape cases. Psychology Crime \& Law. 14(5), 461-479.

Lovett, J. y Kelly, L. (2009). Different Systems, Similar Outcomes? Tracking Attrition in Reported Rape Cases across Europe. London, UK.: Child and Women Abuse Studies Unit.

Mackinnon, C.A., (1987). Feminism Unmodified: Discourses on Life and Law, Cambridge, MA, UK.: Harvard University Press.

Mackinnon, C.A., (2017). Butterfly Politics: Changing the World for Women, Cambridge, MA, UK.: Harvard University Press. 
Marcos, L. (coord.) (2017). Ojos que no quieren ver. Los abusos sexuales a niños y niñas en España y los fallos del sistema. Recuperado de: https://www.savethechildren.es/sites/default/files/imce/docs/ojos_que_no_qui eren_ver_27092017.pdf.

Pitch, T. (2010). Sexo y género de y en el derecho: el feminismo jurídico. Anales de la Cátedra Francisco Suárez, 44, 435-459.

Randeberg, L.L. (2005). Diagnostic applications of diffuse reflectance spectroscopy, Doctoral Thesis, Norwegian: Norwegian University of Science and Technology.

Román, Y. (coord.) (2012). La justicia española frente al abuso sexual infantil en el entorno familiar. Un análisis de casos a la luz de los estándares internacionales de derechos humanos. Recuperado de: https://www.savethechildren.es/sites/default/files/imce/docs/informe_justicia_ esp_abuso_sexual_infantil_vok-2.pdf

Ruiz-Repullo, C., López Morales, J. y Sánchez-González, P. (2020). Violencia de género y abuso de alcohol en contextos recreativos. Revista Española de Drogodependencias, 45(2), 13-22.

Salanueva, O. y Zaikoski, D. (2015). Violencia sexual y discurso jurídico: Análisis de sentencias penales en casos de delitos contra la integridad sexual. Santa Rosa, Argentina: Universidad Nacional de La Pampa.

Schuller, R. A., Mckimmie, B.M., Masser, B.M. y Klippestine, M.A. (2010). Judgments of Sexual Assault: The Impact of Complainant Emotional Demeanor, Gender, and Victim Stereotypes. New Criminal Law Review: An International and Interdisciplinary Journal, 13 (4), 759-780.

Segato, R.L. (2003). "La estructura del género y el mandato de la violación", Las estructuras elementales de la violencia. Ensayos sobre género entre la antropología, el psicoanálisis y los derechos humanos, Buenos Aires, Argentina: Universidad de Quilmes.

Solnit, R. (2016). Los hombres me explican cosas, Madrid, España: Capitán Swing.

Spohn, C. y Tellis, K, (2012). The Criminal Justice System's Response to Sexual Violence. Violence Against Women, 18 (2), 169-192.

Toledo, P., Bodelón, E., Tur, N. y Martínez, J. (2016). Marc jurídic internacional, estatal $i$ autonòmic de les violències sexuals (matrimonis forçats, mutilacions genitals femenines, tràfic d'éssers humans amb finalitat d'explotació sexual, assetjament $i$ agressions sexuals), Barcelona, España: G.R. Antígona i Creación Positiva.

Waterhouse, G., Reynolds, A., Egan, V. (2016). Myths and legends: The reality of rape offences reported to a UK police force. The European Journal of Psychology Applied to Legal Context, 8 (1), 10. 


\section{ANEXO}

Anexo 1: Referencias al Repositorio Oficial de Jurisprudencia (Roj) empleadas en el análisis

\begin{tabular}{|c|c|c|c|}
\hline Caso & Roj & Fecha sentencia & Fecha comisión delito \\
\hline 1 & SAP IB 933/2018 & $9 / 05 / 2018$ & $19 / 05 / 2015$ \\
\hline 2 & SAP IB 973/2018 & $16 / 05 / 2018$ & $12 / 07 / 2015$ \\
\hline 3 & SAP IB 1676/2018 & $11 / 07 / 2018$ & $27 / 07 / 2016$ \\
\hline 4 & SAP IB 2629/2018 & $29 / 11 / 2018$ & $14 / 09 / 2015$ \\
\hline
\end{tabular}

\section{Cómo referenciar este artículo/How to reference this article (*):}

Ballesteros Doncel, E. (2021). "Yo sí te creo". Estereotipos sexistas hacia las víctimas e agresión sexual. Un estudio de caso sobre la Audiencia Provincial de Baleares (2018). iQUAL. Revista de Género e Igualdad, 4, 89-108, doi: 10.6018/iqual. 442801

Ballesteros Doncel, E. (2021). "Yo sí te creo". Estereotipos sexistas hacia las víctimas e agresión sexual. Un estudio de caso sobre la Audiencia Provincial de Baleares (2018). ["I belive you". Sex-stereotypes to sexual assault victims. A case study for the balearic court (2018)]. iQUAL. Revista de Género e lgualdad, 4, 89-108, doi: 10.6018/iqual. 442801

(*) La autoría colectiva responde a una contribución conjunta en todos los apartados. 